\title{
Effects of surgical removal of interscapular brown adipose tissue on food intake and amphetamine anorexia
}

\author{
PAUL J. WELLMAN and PATRICIA A. WATKINS \\ Texas A\&M University, College Station, Texas
}

\begin{abstract}
Adult male albino rats underwent surgical removal of interscapular brown adipose tissue (IBATX) or sham surgery. After recovery from surgery, daily 60 -min feeding tests were conducted to evaluate the potential effect of IBATX on amphetamine anorexia. d-Amphetamine sulfate, at 1.0, 2.0, and $4.0 \mathrm{mg} / \mathrm{kg}$ (ip), induced dose-dependent but comparable anorexia in both IBATX and sham-surgery control rats. The implications of these data for the notion that amphetamine induces satiety, in part, via stimulation of BAT thermogenesis are discussed.
\end{abstract}

Considerable research effort has been expended toward the description and explanation of the anorexic property of amphetamine (Cole, 1967). In particular, central catecholaminergic neurons, within the lateral hypothalamus ( $\mathrm{LH})$, have been linked to the feeding-suppressant action of amphetamine. Direct intracranial injection of amphetamine within the LH induces anorexia, whereas electrolytic lesions of the LH block the anorexia induced by peripheral injection of amphetamine (Carlisle, 1964; Leibowitz, 1975a, 1975b). In spite of this evidence, the suggestion is infrequently made that amphetamine may induce anorexia, in part, via some action within the peripheral nervous system. Most recently, Wellman (1983) demonstrated that amphetamine induces marked stimulation of thermogenesis (Himms-Hagen, 1976) within interscapular brown adipose tissue (IBAT). In light of Glick's (1982) suggestion that BAT thermogenesis induces satiety, amphetamine may induce anorexia indirectly via stimulation of BAT thermogenesis mediated by activation of sympathetic afferent neurons that terminate within IBAT. Were BAT thermogenesis to contribute to the anorexic property of amphetamine (i.e., IBAT activation signals food ingestion), removal of IBAT should diminish the anorexic property of amphetamine. The present experiment therefore sought to demonstrate the influence of surgical removal of IBAT (IBATX) on the anorexia induced by d-amphetamine sulfate $(0.0,1.0,2.0$, and $4.0 \mathrm{mg} / \mathrm{kg})$.

\section{METHOD}

\section{Animals}

The animals were 16 male Sprague-Dawley albino rats (obtained from Timco, Houston, TX) that were 150 days of age and weighed $250-350 \mathrm{~g}$ at the beginning of the experiment. The rats were housed individually in standard wire-mesh metabolism cages (Wahmann) in a temperature-controlled $\left(23^{\circ} \mathrm{C}\right)$ room

The authors' mailing address is: Department of Psychology, Texas A\&M University, College Station, TX 77843. under a continuous illumination schedule. The rats were allowed continuous access to tap water and were fed a pelleted rat diet (Purina Rat \& Mouse Diet) as described in the procedures below.

\section{Procedure}

The rats were trained to consume a weighed amount of pellets placed on the floor of the home cage during a 60 -min test on 10 consecutive days. Food intakes, corrected for spillage collected on paper towels placed beneath each cage, were measured to the nearest $0.1 \mathrm{~g}$. On the last four food-intake tests, the rats were treated (ip) with $1.0 \mathrm{ml} / \mathrm{kg}$ of $0.9 \%$ saline $30 \mathrm{~min}$ prior to each intake test. The rats were allowed free access to water throughout the experiment, but food was available only during the daily $60-\mathrm{min}$ tests. The average of these last four intake tests was used to form two groups of equal mean food intake and body weight.

The rats were deprived of food and water for $24 \mathrm{~h}$ prior to the surgical procedure. Each rat was treated with atropine sulfate (Sigma; $1.0 \mathrm{mg} / \mathrm{ml} / \mathrm{kg}$ ) to reduce respiratory complications and was anesthetized with a combination of ketamine $(60 \mathrm{mg} / \mathrm{kg}$, ip) and sodium pentobarbital (20 mg/kg, ip) (Sigma). For 10 of the rats (IBATX), the dorsal coat was shaved and a midline incision made to expose the scapulae. Sulzer's vein was tied off, and the anterior and dorsal lobes of the interscapular brown adipose mass were located and excised. Following placement of Gelfoam in the surgical site, the incision was closed with 9-mm wound clips, and the incision was dusted with topical Furacin. The remaining rats underwent sham surgery, which consisted of anesthetization and incision but no manipulation of IBAT. During a 4-day recovery period following surgery, the rats were given free access to food and water.

Following recovery, the feeding regimen was reinstituted for four tests, each preceded by a saline injection. These tests served to establish whether the IBATX rats displayed a change in their baseline food intakes following the surgery. A drug sequence was then initiated according to the procedures outlined above, with injections being given in the following order: drug-saline-salinedrug-saline-saline-drug. Each rat was given each of the amphetamine dosages $(1.0,2.0$, and $4.0 \mathrm{mg} / \mathrm{kg})$ once in a random order, to minimize order effects. The saline tests interposed between successive drug tests served to assess the stability of food intake in the groups and possible drug carryover effects. Because Stephens, Nash, and Proffitt (1981) had reported significant hypertrophy of BAT tissue at sites other than IBAT some 45 days following the removal of IBAT, the temporal sequence of the present study sought to determine the impact of IBAT removal 
some 10-17 days postoperatively. At the end of the amphetamine anorexia tests, each of the surgical rats was deeply anesthetized with $60 \mathrm{mg} / \mathrm{ml} / \mathrm{kg}$ (ip) of sodium pentobarbital in order to verify the completeness of the surgical removal of IBAT.

\section{Statistical Analyses}

Data analyses were computed for those surgical rats that exhibited no IBAT at sacrifice. The food-intake data of this experiment were analyzed using factorial analyses of variance with surgery (IBATX/sham surgery) as the between factor and amphetamine dosage $(0.0,1.0,2.0$, and $4.0 \mathrm{mg} / \mathrm{kg})$ as the repeated factor. Separate analyses were carried out for the data expressed as raw scores and as percent-change scores. Subsequent comparisons between and within groups were made using a priori two-tailed $t$ tests (Kirk, 1968). All statistical tests were evaluated at the .05 level of significance.

\section{RESULTS AND DISCUSSION}

A control rat and two surgical rats died from respiratory complications immediately after surgery, and three surgical rats displayed small residual deposits of IBAT (approximately 15-20 $\mathrm{mg}$ ) at sacrifice.

Figure 1 presents the changes in food intake produced by amphetamine in the control and surgical groups. No differences in mean group food intake after saline injection were observed between the groups prior to or following the surgical removal of IBAT; thus, this surgical procedure did not debilitate the IBATX rats. Amphetamine treatment produced a marked dosedependent and statistically significant suppression of food intake in both control and IBATX rats [raw intake, $F(3,24)=63, p<.0001 ;$ percent change from saline baseline, $F(2,16)=55, p<.0001]$. There was no significant interaction between the factors of group and amphetamine dose. Although there was a trend for IBATX rats to display attenuated amphetamine anorexia, relative to the changes in food intake observed in the control rats, to $1.0-$ or $2.0-\mathrm{mg} / \mathrm{kg}$ doses, these differences were not statistically significant [percent change, $F(1,8)$ $=0.8, \mathrm{p}>.41]$.

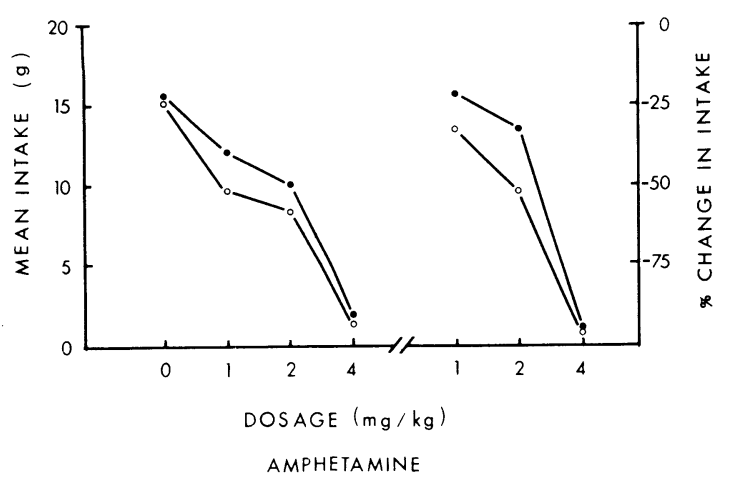

Figure 1. Mean group food intake (left panel) and percent change in food intake (right panel) produced by saline or various concentrations of amphetamine $(1.0,2.0$, and $4.0 \mathrm{mg} / \mathrm{kg})$ in sham-surgery $(0)$ and $\operatorname{IBATX}(\bullet)$ rats.
Removal of IBAT in rats in the present study did not enhance food intake or attenuate the anorexic action of amphetamine. These data confirm and extend a growing body of reports that fail to demonstrate that enhanced or diminished BAT thermogenesis has any consistent and reliable effect on feeding. Wellman and Watkins (in press), for example, noted that 4-hydroxyamphetamine (4-OHAM), a sympathomimetic drug that only poorly penetrates the brain, induced marked BAT thermogenesis and yet had no significant effect on either feeding or drinking. The absence of a predicted effect of diminished BAT metabolism is not specific to surgical removal of IBAT. Watkins, Wellman, and Clark (1984) demonstrated that sympathectomy induced by guanethidine produced a $60 \%$ reduction of norepinephrine with IBAT and yet had no impact on either body weight or food intake. Taken together, these data suggest that, although feeding behavior may impact on BAT thermogenesis (so-called diet-induced thermogenesis; Rothwell \& Stock, 1979; Young \& Landsberg, 1979), feeding behavior is not under the control of BAT thermogenesis.

\section{REFERENCES}

Carlisle, H. J. (1964). Differential effects of amphetamine on food and water intake in rats with lateral hypothalamic lesions. Journal of Comparative and Physiological Psychology, 58, 47-54. Cole, S. O. (1967). Experimental effects of amphetamine: A review. Psychological Bulletin, 68, 81-90.

GLICK, Z. (1982). Inverse relationship between brown fat thermogenesis and meal size: The thermostatic control of food intake revisited. Physiology \& Behavior, 29, 1137-1140.

Himms-Hagen, J. (1976). Cellular thermogenesis. American Review of Physiology, 38, 315-351.

KIRK, R. E. (1968). Experimental design: Procedures for the behavioral sciences. Belmont, CA: Brooks/Cole.

Leibowitz, S. F. (1975a). Amphetamine: Possible site and mode of action for producing anorexia in the rat. Brain Research, 84, 160-167.

LE IBOWITZ, S. F. (1975b). Catecholaminergic mechanisms of the lateral hypothalamus: Their role in the mediation of amphetamine anorexia. Brain Research, 98, 529-545.

Rothwell, N. J., \& STOCK, M. J. (1979). A role for brown adipose tissue in diet-induced thermogenesis. Nature, 281, 31-35.

Stephens, D. N., Nash, S. C., \& Proffitt, C. (1981). Dietary obesity in adult and weanling rats following removal of interscapular brown adipose tissue. Pflugers Archives, 392, 7-12.

Watkins, P. A., Wellman, P. J., \& Clark, D. C. (1984). Effects of guanethidine sympathectomy on food intake, weight gain and amphetamine anorexia in the adult rat. Manuscript submitted for publication.

Wellman, P. J. (1983). Influence of amphetamine on brown adipose tissue thermogenesis. Research Communications in Clinical Pathology and Pharmacology, 41, 173-176.

Wellman, P. J., \& Watkins, P. A. (in press). The effects of 4-hydroxyamphetamine (4-OHAM) on in vivo brown adipose tissue thermogenesis and feeding behavior in the rat. Behavioral Neuroscience.

Young, J. B., \& LANDsBerg, L. (1979). Effect of diet and cold exposure on norepinephrine turnover in pancreas and liver. American Journal of Physiology, 236, E524-E533.

(Manuscript received for publication April 10, 1984.) 